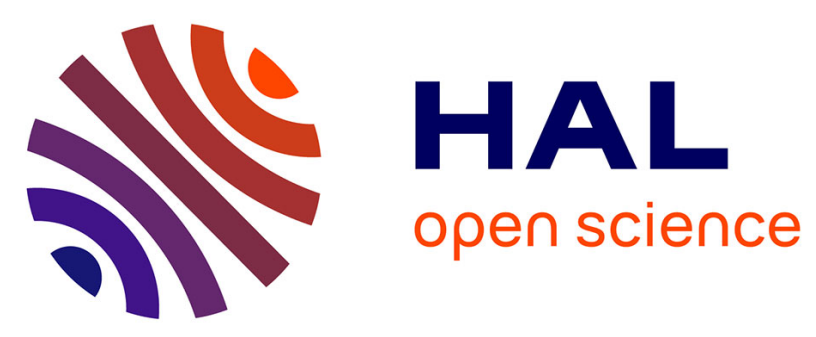

\title{
By half decrease of cardiovascular mortality in a Western country between 2000 and 2015: A contrasted picture advocating for a better management of comorbidities
}

Claire Duflos, Camille Roubille, François Roubille

\section{- To cite this version:}

Claire Duflos, Camille Roubille, François Roubille. By half decrease of cardiovascular mortality in a Western country between 2000 and 2015: A contrasted picture advocating for a better management of comorbidities. International Journal of Cardiology, In press, 10.1016/j.ijcard.2020.05.015 . hal02615310

\author{
HAL Id: hal-02615310 \\ https://hal.science/hal-02615310
}

Submitted on 3 Jul 2020

HAL is a multi-disciplinary open access archive for the deposit and dissemination of scientific research documents, whether they are published or not. The documents may come from teaching and research institutions in France or abroad, or from public or private research centers.
L'archive ouverte pluridisciplinaire HAL, est destinée au dépôt et à la diffusion de documents scientifiques de niveau recherche, publiés ou non, émanant des établissements d'enseignement et de recherche français ou étrangers, des laboratoires publics ou privés. 


\title{
By half decrease of cardiovascular mortality in a Western country between 2000 and 2015: A contrasted picture advocating for a better management of comorbidities
}

\author{
Claire Duflos ${ }^{\mathrm{a}, \mathrm{b}}$, Camille Roubille ${ }^{\mathrm{c}, \mathrm{e}}$, François Roubille ${ }^{\mathrm{d}, \mathrm{e}, *}$ \\ ${ }^{a}$ CEPEL, Univ Montpellier, CNRS, Montpellier, France \\ ${ }^{\mathrm{b}}$ Clinical Research and Epidemiology Unit, CHU Montpellier, Univ Montpellier, France \\ c Department of Internal Medicine, Montpellier University Hospital, Montpellier, France \\ d Department of Cardiology, Montpellier University Hospital, Montpellier, France \\ e PhyMedExp, University of Montpellier, INSERM U1046, CNRS UMR 9214, Montpellier, France
}

Cardiovascular diseases (CVD) remain a leading cause of death worldwide. Nevertheless, the cardiovascular mortality has decreased in developed countries in the past decades. In the paper entitled "Explaining the Fall in Coronary Heart Disease Mortality in the Republic of Ireland between 2000 and 2015 - IMPACT Modelling Study", Marasigan et al. report a dramatic decrease in cardiovascular mortality (specifically coronary heart disease [CHD]) observed in Ireland in recent years (between 2000 and 2015), for both men and women [1]. The main objective of their work was to study the contribution of individual and population factors, respectively. Above all, the authors provide crucial explanations for such a reduction, by weighting some various parameters (mainly treatments or risk factors) as responsible for this improvement. Some limitations are acknowledged by the authors, including the lack of consideration of important drugs (such as antiplatelet agents, mineralocorticoid receptor antagonists in heart failure [HF], etc), or of some established cardiovascular risk factors (such as chronic inflammatory diseases, depression or chronic kidney disease). Nevertheless, the authors report results which are consistent with the literature, and above all, their models are able to explain about $90 \%$ of the observations.

From a methodological point-of-view, their approach seems elegant. Trying to interpret trends of CHD mortality rates over several years quickly comes up the multiplicity of its determinants, which also change over years. This is the so-called "age-period-cohort effect", and several statistical models have been proposed to deal with it [2]. The authors use the CHD IMPACT model, which takes advantage of classical methods. This model was first validated in 2012 in Ireland, and subsequently in several countries. First, an indirect standardization based on mortality rates in 2000 allowed to quantify the prevented or postponed deaths (PPD) each subsequent year, taking into account the increase in life expectancy. Second, a methodological extension of the calculation of the risk fraction attributable in population to continuous risk factors and

* Corresponding author at: Cardiology Department, University Hospital of Montpellier, Montpellier, France.

E-mail address: f-roubille@chu-montpellier.fr (F. Roubille). to therapeutic interventions has made it possible to determine their specific impact on the number of PPD, providing a particularly concrete insight into long-term mortality trends.

This approach provides important data for a better understanding of the "pathophysiology" of clinical outcomes. It allows simulation studies which bring directly usable data to inform health policy [3]. The successful implementation of this model is made possible by the availability of high-quality epidemiological data with prevalence statistics, and metaanalyses of trials. However, while data on the relative risks of risk factors or interventions can be cautiously extrapolated from one setting to another, descriptive statistics on the prevalence of risk factors and incidence of clinical outcomes should be made available in any other country wishing to apply these simulation studies.

As a clinician, indeed, we could have expected that a better control of modifiable cardiovascular risk factors should have explained the major part of this improvement, all the more as many cardiovascular therapies are considered nowadays as "mature" clinical practices, suggesting that a plateau should have been reached as regards its impact on cardiovascular morbi-mortality. The first important message here, by contrast, is that only one third of the improvement in CHD mortality is due to improvements in CHD risk factors. More precisely, this effect is mainly driven by improved hypertension control that could explain by itself $25 \%$ of the DPP. These results remind clinicians of the importance of hypertension as the first preventable risk factor (considered as a cause) responsible for the highest CVD mortality, as well as all-cause death in some parts of the world [4]. On the other hand, blood pressure decrease has been associated with reduction in cardiovascular mortality $[5,6]$. Nowadays, the overall prevalence of hypertension in adults is around $30-45 \%$ [4] whereas the global age-standardized prevalence is estimated around $24 \%$ in men and $20 \%$ in women, respectively, in 2015 [6]. This age-standardized prevalence decreases slowly but regularly, as shown on Fig. 1, but the global prevalence increases because of aging and other comorbidities. The World Health Organization (WHO) predicts an increase of people with hypertension by 2025, until 1.5 billion people in 2025. In this issue, Marasigan et al. support tight control of patients' blood pressure. 


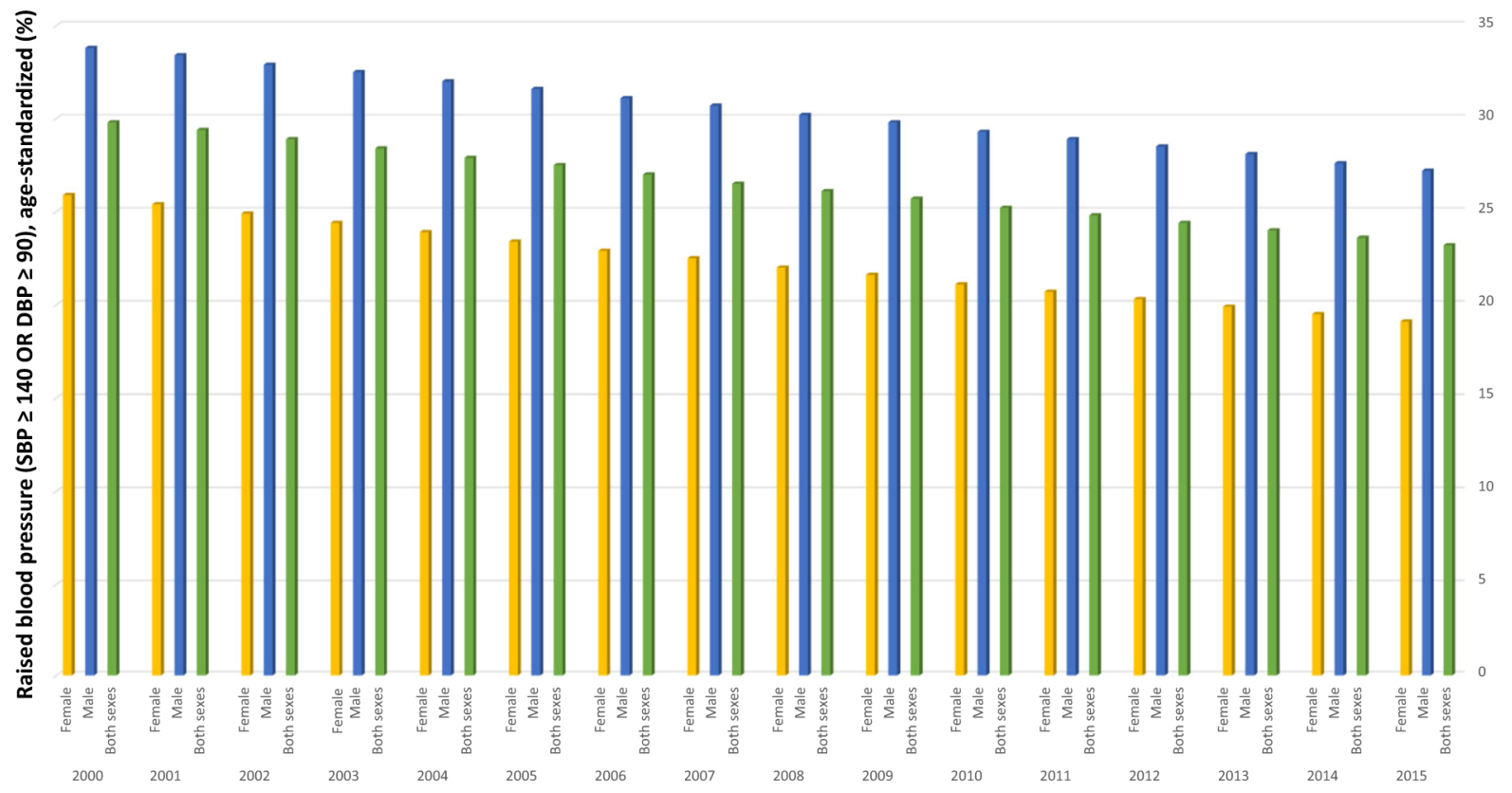

Fig. 1. Age-standardized percentage of patients presenting elevated blood pressure as defined by systolic blood pressure $\geq 140 \mathrm{mmHg}$ and/or diastolic blood pressure $\geq 90 \mathrm{mmHg}$, from 2000 to 2015 in Europe, World health Organization. SBP: systolic blood pressure; DBP: diastolic blood pressure.

Beyond the beneficial control of blood pressure, other aspects of primary prevention should not be neglected, particularly with regard to overweight, diet, smoking and physical activity, arguing in favor of an even more active investment of health policies to improve these risk factors whose management remains perfectible. Indeed, Marasigan et al. report that only $11 \%$ of the DPP could be explained by a better control on lipids, and a marginal reduction of smoking (5\%). Furthermore, a poorer "metabolic" status (including rise in diabetes prevalence $(-6 \%)$, Body Mass Index $(-4 \%)$ and physical inactivity $(-2 \%))$ worsened the CHD mortality.

Finally, the major magnitude of the effect is achieved by better control of hypertension, which alone is responsible for about half of the beneficial effect related to risk factors. As the age-standardized prevalence of hypertension is decreasing but the global prevalence is increasing, and because reducing hypertension has been shown to be effective, it is crucial to maintain effort on hypertension, which is often neglected by the patients themselves. This goal is all the more important given that it has been suggested that the lower the better [7].

The second important message here, which comes as a pleasant surprise, is to show that changes in cardiovascular therapies alone account for almost two thirds of the improvements, particularly in secondary prevention and heart failure drugs. Guidelines on acute coronary syndromes have been modified in line with large clinical trials, particularly with respect to antiplatelet agents with more effective drugs [8], or better revascularization. Recently, new avenues have been suggested to struggle inflammatory processes in patients with acute coronary syndromes [9], suggesting that improvements are still possible despite early revascularization and many effective drugs. Similarly, treatments have been improved for heart failure [10], mainly chronic HF, rather than acute HF and new drugs have recently been proved to decrease mortality [11]. For all these reasons, we can hope that improvements in the treatments of CVD will continue to reduce mortality from CVD.

\section{Declaration of competing interest}

The authors report no relationships that could be construed as a conflict of interest.

\section{References}

[1] Marasigan V, Perry I, Bennett K, Balanda K, Capewell S, M OF, et al. Explaining the fall in Coronary Heart Disease mortality in the Republic of Ireland between 2000 and 2015 - IMPACT modelling study. Int J Cardiol. 2020.

[2] T. Tonda, K. Satoh, K. Kamo, Detecting a local cohort effect for cancer mortality data using a varying coefficient model, J. Epidemiol. 25 (2015) 639-646.

[3] M. O'Flaherty, P. Bandosz, J. Critchley, S. Capewell, M. Guzman-Castillo, T. Aspelund, et al., Exploring potential mortality reductions in 9 European countries by improving diet and lifestyle: a modelling approach, Int. J. Cardiol. 207 (2016) 286-291.

[4] C.K. Chow, K.K. Teo, S. Rangarajan, S. Islam, R. Gupta, A. Avezum, et al., Prevalence, awareness, treatment, and control of hypertension in rural and urban communities in high-, middle-, and low-income countries, JAMA 310 (2013) 959-968.

[5] D. Ettehad, C.A. Emdin, A. Kiran, S.G. Anderson, T. Callender, J. Emberson, et al., Blood pressure lowering for prevention of cardiovascular disease and death: a systematic review and meta-analysis, Lancet 387 (2016) 957-967.

[6] Collaboration NCDRF. Worldwide trends in blood pressure from 1975 to 2015: a pooled analysis of 1479 population-based measurement studies with 19.1 million participants. Lancet. 2017;389:37-55.

[7] Group SR, J.T. Wright Jr., J.D. Williamson, P.K. Whelton, J.K. Snyder, K.M. Sink, et al., A randomized trial of intensive versus standard blood-pressure control, N. Engl. J. Med. 373 (2015) 2103-2116.

[8] B. Ibanez, S. James, S. Agewall, M.J. Antunes, C. Bucciarelli-Ducci, H. Bueno, et al., 2017 ESC guidelines for the management of acute myocardial infarction in patients presenting with ST-segment elevation: the task force for the management of acute myocardial infarction in patients presenting with ST-segment elevation of the European Society of Cardiology (ESC), Eur. Heart J. 39 (2018) 119-177.

[9] J.C. Tardif, S. Kouz, D.D. Waters, Bertrand OF, R. Diaz, A.P. Maggioni, et al., Efficacy and safety of low-dose colchicine after myocardial infarction, N. Engl. J. Med. 381 (2019) 2497-2505.

[10] P. Ponikowski, A.A. Voors, S.D. Anker, H. Bueno, J.G.F. Cleland, A.J.S. Coats, et al., 2016 ESC guidelines for the diagnosis and treatment of acute and chronic heart failure: the task force for the diagnosis and treatment of acute and chronic heart failure of the European Society of Cardiology (ESC) developed with the special contribution of the Heart Failure Association (HFA) of the ESC, Eur. Heart J. 37 (2016) 2129-2200.

[11] J.J.V. McMurray, S.D. Solomon, S.E. Inzucchi, L. Kober, M.N. Kosiborod, F.A. Martinez, et al., Dapagliflozin in patients with heart failure and reduced ejection fraction, $\mathrm{N}$. Engl. J. Med. 381 (2019) 1995-2008. 